\title{
Development and Standardization of Knowledge Scale on Use and Operation of ICTs in Agriculture and Allied Areas by Rural Women
}

\author{
Pompy Malakar*, Manoshi Baruah Deka and Manju Dutta Das \\ Department of Extension and Communication Management,, College of Community Science, \\ Assam Agricultural University, Jorhat(Assam) India \\ *Corresponding author
}

Keywords

Knowledge Scale Operation of ICTs in Agriculture

Article Info

Accepted:

15 October 2020

Available Online:

10 November 2020

\begin{abstract}
A B S T R A C T
The present study was aimed to construct, develop and standardize a knowledge scale on use \& operation of ICT in agriculture and allied areas by rural women. After reviewing different related literature, the researcher outlined a scale and after that analyzing the content framed 80 items related to the course. The prepared 80 items were revised and edited carefully and then given to a panel of experts in the field on Information Communication Technology (ICT) and extension specialist for their valuable suggestions and corrections to ensure its quality. Thus the content validity of the tool was established. After seeking the opinion of the experts some of the items were reframed. Finally, 40 items were considered to form initial battery for developing a standardized knowledge test. These items were subjected to item analysis. After which, a total 22 items were remained for the final study. Simple random sampling method was adopted for the selection of respondents for standardization of knowledge check. Item Analysis was done by calculating the Difficulty Index and Discrimination Index level of the 40 items.
\end{abstract}

\section{Introduction}

Information and Communication Technology (ICT) is a combination of both science and technology. It includes cell phone, computer hardware and software, internet, wired and wireless networks, digital still and video cameras etc. In the recent years ICTs have witnessed major changes and are emerging as a powerful tool for transferring agricultural information's among the rural women's.

Rural women play an important role in agricultural production and have been increasing considerably. Though women's contribution in food production, food processing leading to eventual export of agricultural production has been well documented but not fully recognised they face greater constraints than men farmers (Chand et al., 2012). Women farmers have been reported to be 20-30 per cent less productive than men (FAO, 2011). Despite women's significant and crucial role in agricultural development and allied activities, they have virtually no access to agricultural information, services or production assets and have very limited control over their earnings (Huyer and 
Carr 2002). Therefore it is necessary to find out the knowledge of the rural women towards ICTs as it has the potential to make significant contribution in the capacity building of the rural women by increasing their knowledge through different digitalized tools in the field of agricultural and allied activities and hence increasing the productivity.

\section{Materials and Methods}

For the present study, the following procedures were followed for sampling, preparing the draft tool and administration of the tool.

\section{Sample}

For the present study, a total of 30 rural women were selected as respondents belonging from non sampled area of Jorhat district of Assam. For selection of the sample simple random sampling technique was adopted.

\section{Preparation of the draft tool}

\section{Construction of knowledge test}

The following major steps were undertaken by adopting the procedure followed by Moulik (1965), Murthy (1969), Reddy (1976), and Saikia (2017).

\section{Collection of items}

The content of knowledge test is composed of statements called items. Based on the content area eighty (80) statements regarding ICT use and operations in agriculture and allied areas were prepared from the pertinent literature and consulting with subject experts. The items were edited and drafted in such a way that each item highlighted only one idea and did not have any ambiguity. All items were logically sequenced to form initial test set to carry out the item analysis.

\section{Preliminary selection of items}

The prepared items were subjected to scrutiny by a panel of experts ( 25 nos.) in the field of extension specialist and scientists from All India Coordinated Research Project (AICRP) on Home Science. The experts were requested to check each item carefully whether items were really measuring the knowledge of the respondents about ICT use and operations or not. They had, of course, liberty to add/delete or modify any of the items. After considering the opinion of experts, forty (40) items were selected for developing a standardized knowledge test (Table 1).

All the selected items were in the form of having correct and incorrect type of questions.

\section{Item analysis}

The item analysis was carried out as per the standard procedure, so as to yield three kinds of information viz., "index of item difficulty", "item discrimination index" and "point biserial correlation". The initial test was pretested with 20 respondents. The items were revised and finally administered to 30 respondents from non sampled area of Jorhat district of Assam. The data thus obtained was subjected for item analysis. To analyze 40 items each of the 30 respondents to whom the test item were administered was scored on the basis of the score allotted i.e. 1 for correct response and 0 for incorrect response. Therefore there was a possibility of respondents scoring the maximum points for all correct answers and zero points for all wrong answers. Thus the range of obtainable score was 0-40. After computing the total score obtained by each of the thirty respondents on 40 items, they were arranged in order from highest to the lowest. These 30 
respondents were then divided into six equal groups- G1, G2, G3, G4, G5 and G6 respectively with 5 respondents in each group. For the purpose of item analysis the middle two groups G3 and G4 were eliminated keeping only four extreme groups with high (G1 and G2) and low (G5 and G6) score.

\section{Item difficulty index (P)}

Item difficulty was determined by the percentage of individuals able to pass each item. In practice, if an item is to distinguish among individuals, it should not be so easy that all persons can pass it, nor should be difficult that none are able to pass it.

The index of item difficulty indicated the extent to which an item was difficult. The item difficulty as worked out in the present study was $\mathrm{P}$ i.e. the percentage of respondents answering an item correctly. The item with $\mathrm{P}$ values ranging from 30 to 70 was considered for the final selection of the standard knowledge test. It was calculated by following formula:

$$
\mathrm{P}=\frac{\text { No.of respondents answer correctly }}{\text { Total no.of respondents }} \times 100
$$

\section{Item discrimination index (E1/3)}

The second criteria for item selection were the discrimination index indicated by $\mathrm{E} 1 / 3$ value for an item. The function of item discrimination index is to find out whether an item really discriminates a well informed respondent from a poorly informed respondent.

The formula used is as follows:

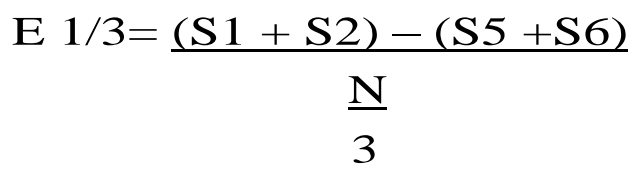

Where,

$\mathrm{S} 1, \mathrm{~S} 2, \mathrm{~S} 5$ and S6 = frequencies of correct answers in groups G1, G2, G5 and G6 respectively.

$\mathrm{N}=$ Total number of respondents in the sample selected for item analysis. In the present study, the item with E1/3 values ranging from 0.30 to 0.70 was considered for the final selection for inclusion in the knowledge test.

\section{Point biserial correlation (rpbis)}

For establishing internal validity of the check point biserial correlation coefficient (rpbis) was estimated since the items were scored simply as 1 if correct and 0 if incorrect. According to Garrett (1979) point biserial $r$ assume that the variable, which has been classified into two categories, can be thought of as concentrated at two distinct points along a graduated scale or continuum.

The formula for the point biserial $\mathrm{r}$ is:

rpbis $=\frac{\mathrm{Mp}-\mathrm{Mq}}{\mathrm{SD}} \times \mathrm{pq}$

Where,

rpbis $=$ Point biserial correlation coefficient $\mathrm{Mp}=$ Mean of the total scores of the respondents who answered correctly

$\mathrm{Mq}=$ Mean of the total scores of the respondents who answered incorrectly $\mathrm{SD}=$ Standard deviation of the entire sample $\mathrm{p}=$ Proportion of the respondents giving correct answers to the item

$\mathrm{q}=$ Proportion of the respondents giving incorrect answers to the item or $q=1-p$

Items having significant Point biserial correlation, either at 0.01 per cent or 0.05 per cent level of probability were selected for the final knowledge check. 


\section{Test of significance of rpbis}

To test significance of Point biserial correlation co-efficient the following ' $t$ ' test was used.

$\mathrm{t}=\frac{\mathrm{rpbis} \sqrt{\mathrm{N}-2}}{\sqrt{1}-\mathrm{rpbis} 2}$

where,

rpbis $=$ Point biserial correlation

$\mathrm{N}=$ Total number of respondents

\section{Testing the reliability of the knowledge test}

A split half reliability coefficient method was used to find out the reliability. The test was administered to thirty respondents and test was corrected by using Spearman Brown Formula. The reliability coefficient of the whole test was estimated from the formula given below:

$\mathrm{rtt}=2 \mathrm{roe} / 1+$ roe

where,

$\mathrm{rtt}=$ reliability coefficient of the whole test roe $=$ reliability coefficient of the half-test found experimentally.

Both these coefficients provide an estimate of the internal consistency of the test and thus the dependability of the test scores.

Table.1 Following are the items of the standardized scale

\begin{tabular}{|l|l|}
\hline S1 No. & Statements \\
\hline 1. & Checking missed calls \\
\hline 2. & Recording voice in mobile phone \\
\hline 3. & Reminder can be saved only in English language \\
\hline 4. & Call conferencing facilities are available in smart phones \\
\hline 5. & Games are available in all mobile phones \\
\hline 6. & All mobile apps are chargeable* \\
\hline 7. & We can watch agricultural related videos in YouTube \\
\hline 8. & Facebook provides a platform to market the product \\
\hline 9. & Smartphone can be used for social networking only* \\
\hline 10. & Online shopping is easier through different mobile apps \\
\hline 11. & Smartphone provides transaction facilities \\
\hline 12. & Smartphone can be used for assessing weather related information \\
\hline 13. & Kisan Call Centre of Government of India has free call facilities \\
\hline 14. & TV telecasts programmes related to entertainment only* \\
\hline 15. & TV provides weather information \\
\hline 16. & TV do not telecast programmes related to government schemes* \\
\hline 17. & Agricultural related programmes telecast on a fixed schedule \\
\hline 18. & Radio broadcasts programmes only in English language* \\
\hline 19. & Agricultural talk shows are also broadcasts in radio \\
\hline 20. & Kisan Vani includes only agricultural programmes \\
\hline 21. & All India Radio broadcasts programmes on agriculture in regional languages for \\
\hline 22. & farmers \\
\hline *mark indicates the negative items \\
\hline
\end{tabular}




\section{Validity of the scale}

Content validity was measured by the extent to which the items included in the test represent the total universe of Information Communication Technology.

The universe of the content was covered widely from the available literature and through interviews with several rural women, experts and extension personnel. Hence, it was assumed that the scores obtained by administering the knowledge test measures what it was intended to be measured.

Moreover, the validity of the test item was also tested by method of point biserial correlation coefficient (rpbis). The items with highly significant biserial correlation coefficients at 0.01 and 0.05 levels of probability indicated the validity of the items in relation to the knowledge test designed to measure the knowledge of rural women.

The final scale consisted of twenty two (22) statements. Rural women's responses were recorded on a two point continuum as yes /no and scored as 1 and 0 . The knowledge check developed and standardized was valid and reliable. Hence, the check could serve the purpose for assessing the knowledge of rural women on use and operation of ICTs in agriculture and allied areas.

\section{References}

Chand, Prem, U.S. Gautam, Anupam Mishra, S.R.K. Singh, P. Dwivedi and R.K. Yogi (2012), "Multiple Role of Women-a Regional Analysis", Proceedings of Global Conference on Women in Agriculture (abstracts), March, pp. 13-15.

FAO (2011), "Women - Key to Food Security, 2010-11", Available at http://www.fao.org/docrep/014/ am719e /am719e00.pdf on 21/9/2011.

Sophia, Huyer and Marilyn, Carr (2002), "Information and Communication Technologies: A Priority for Women", Gender Technology and Development, 6(1), pp. 85-100.

Ingita Gohain* and Juliana Sarmah (2019), "Development and Standardization of Knowledge Scale on Hygiene for Rural Women", Int.J.Curr.Microbiol.App.Sci (2019) 8(3): 145-149

Rajni Jain, Usha Rani Ahuja and Anjani Kumar (2012) ICTs and Farm Women: Access, Use and Impact. Ind. Jn. of Agri. Econ. 67(3).

\section{How to cite this article:}

Pompy Malakar, Manoshi Baruah Deka and Manju Dutta Das. 2020. Development and Standardization of Knowledge Scale on Use \& Operation of ICTs in Agriculture and Allied Areas by Rural Women. Int.J.Curr.Microbiol.App.Sci. 9(11): 1781-1785.

doi: https://doi.org/10.20546/ijcmas.2020.911.210 